\title{
Fuzzy Evaluation of Flood Risk Rating in Laoshan District Based on GIS*
}

\author{
Ma Anqing ${ }^{1,2}$, Jiao Junchao ${ }^{1,2}$, Liu Lejun ${ }^{3}$, Li Zhengyan ${ }^{1,2}$,Hu Hong ${ }^{1,2}$ \\ ${ }^{1}$ Key Laboratory of Marine Environment \& Ecology, Ministry of Education, Ocean University of China, Qingdao, Shandong \\ 266100, China \\ ${ }^{2}$ College of Environmental Science and Engineering, Ocean University of China, Qingdao, Shandong 266100, China; \\ ${ }^{3}$ Key Lab of Marine Sedimentology and Environmental Geology of SOA, First Institute of Oceanography, SOA, Qingdao, \\ Shandong 266100,China
}

\begin{abstract}
The purpose of the present study was to reduce the losses caused by flood and to prevent them in advance, by taking Laoshan District, Qingdao City as an object. on the basis of COM GIS and the spatial analysis functions of GIS, we designed an evaluation model to develop flood risk evaluation system for Laoshan District. Using factor set, judgment set, membership function, and weight set established by the method of fuzzy comprehensive evaluation. The system can produce assessment results automatically after data input by the users, which is classed into 5 ranks, including "the most dangerous", "dangerous", 'normal', 'safe,' and "the safest". The results were obtained by the rating system most in common with the actual results, for example, Wanggezhuang street is in the most dangerous zone in the area. With good flexibility and performance, the method of the system can be promote into general crisis evaluation.
\end{abstract}

Index Terms - GIS; floods risk; fuzzy evaluation

\section{Introduction}

Risk value of natural disaster is potential intensity and occurrence possibility which future disaster might reach ${ }^{[1]}$. Due to complex land forming and heavy precipitation, may damages caused by flood in the Laoshan district. Hence, it is particularly important to evaluate risk of flood disaster in this area. Risk assessment is a system works on probability or potential level of damages which effects on life security, human health, ecology and finance ${ }^{[2]}$.

With development of computer technology, GIS has been widely used in enterprise information management, land planning and gas pipeline risk early warning. Especially, it is irreplaceable for GIS to synthetically manage spatial and nonspatial data and effectively make use of them ${ }^{[3]}$. Being an effective multi-factors decision making method, as studied objects are influenced by many factors, the fuzzy comprehensive decision can offer comprehensive evaluation. So that it is necessary to adopt GIS into disaster assessment process, which is synthetic result from natural environment and social economy ${ }^{[4]}$.

For the present, utilizing integration of computer and GIS technology to study flood hazard has been a hotspot ${ }^{[5,6]}$, in spite of most methods of correlative researches only using function of grid map overlaying in GIS software ${ }^{[7,8]}$. The above application needs the user with capability in

\footnotetext{
* Identify applicable sponsor/s her .(sponors)
}

manipulating GIS software, which will limit scope of users in a way and even affect accuracy of results. The study transformed vector data of the Laoshan District into the same data structure consisting of large number of regular square grids, with fuzzy comprehensive evaluation method to construct assessment model, integration of ComGIS to develop Classification evaluation intelligent system on flood disaster risk in the Laoshan District. The system can export satisfying result only following prompt of GUL as it is used, so it is possible for the system to provide manageable assistant decision system for the relevant departments.

\section{Study Area Survey and Data}

\section{A Introduction of the study area}

The Laoshan District, located on south-east Qingdao, China, covers $390 \mathrm{~km} 2$ area(N 3604' 3608', E120024' 120031'), and dominates four sub-district administrative offices, which are the Zhonghan,the Shazikou,the Beizhai and the Wanggezhuang. Average elevation of the region is $55 \mathrm{~m}$ with $1132.7 \mathrm{~m}$ of the highest elevation in the Laoshan Mountain and $92.6 \%$ of the area is covered by hill $(360.44 \mathrm{~km} 2)$. Parts of the region are covered steep terrain with average gradient more than 70 . There are 23 rivers over the area, with features of short length, rapid flow, most directly flowing into sea. Climate type is temperate continental monsoon, with obvious seasonal variation on precipitation, about $62.3 \%$ of annual rainfall in summer and autumn (June $\sim$ October). The above natural features in climate and terrain were the main factors for causing flood hazard in studied area [9].

\section{B Data collection}

There are primarily two types of data sources of Laoshan District: (1) graph data: administration area dividing map $(1: 47,000)$, the topographic map $(1: 25,000)$, Drainage system map (1:50,000); (2)document data: daily precipitation observation data in Laoshan District (from 1965 to 2008), socio-economic statistic data in the same time of precipitation data, in situ data 


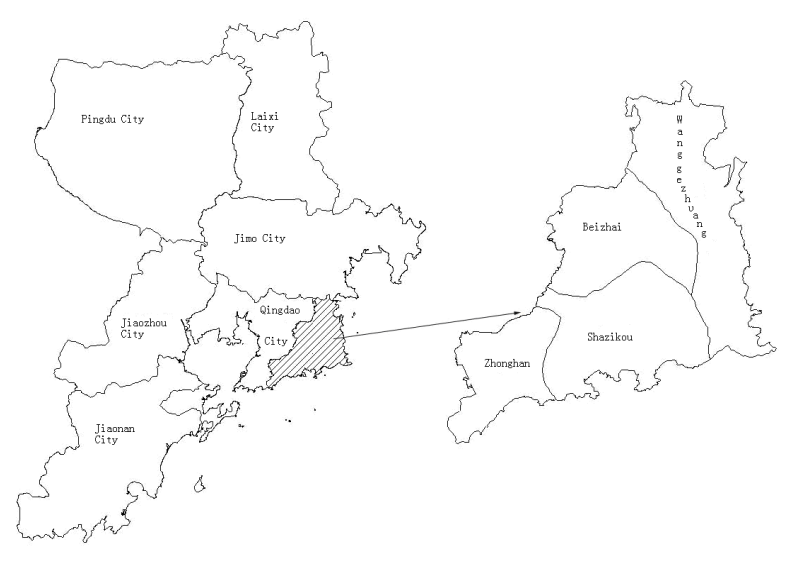

Figure 1. Sketch map of the research area

\section{Methodologies and Implementation}

\section{A Fuzzy evaluation model}

After Zadeh L A (an Amercian scholar in cybernetics) presented concept of Fuzzy sets, Fuzzy comprehensive assessment has been used in many domains ${ }^{[10,11]}$. In the evaluation process, the studied object was taken as a fuzzy set composed of many factors (Factors Set: U). next (Criteria Set: V) as evaluation grades, the fuzzy set was able to be adopted by the above factors. Ultimately with membership value of each assessed factor to corresponding grade calculated by membership function, classification value of each factor subordinating was calculated to the corresponding grade respectively (Fuzzy Matrix: R). Analytic Hierarchy Process (AHP) was used to determine the weight, and ultimately Evaluation grade $\mathrm{B}=\mathrm{A}^{\circ} \mathrm{R}$ was gained ${ }^{[12]}$.

\section{B GIS technology in flood hazard study}

Up till now, especially in the advanced countries, there have been many studies adopting GIS technology in investigation of flood hazard risk and its spatial-time distribution, which also has been an indispensable content in analogous studies ${ }^{[13,14]}$. The COM GIS is such technology that owns essential GIS function in form of component, on basis of platform of component object, being a new generation of GIS based on integration of GIS with component technology. So the technology has been a main method for application of GIS model ${ }^{[15]}$.

\section{Modeling and Designing the System}

\section{A Constitution of fuzzy evaluation model}

\section{1) Disaster-causing factors selection}

Comparing with other seasons, in Laoshan District, peaks of total amount and intensity of precipitation appear in summer and autumn, the flood disaster also appears at the same period. Therefore, data collection and the study were performed mainly during that period. In the evaluation system, referring to existing researches and the practices ${ }^{[16]}$, the evaluation factors were chosen as rain intensity (U1), gradient (U2), drainage density (U3), population density (U4), vegetation cover (U5), rainfall (U6). Among these factors, data of rainfall and distribution of rainfall intensity were acquired by interpolating value from each meteorological station. In contrast to annual precipitation, rainfall here was only sum precipitation over summer and autumn. The rainfall intensity was account of days when daily precipitation is more than $50 \mathrm{~mm}$. Gradient information was gained from DEM model based on the topographic map; river data were gained from drainage system map; population density data from interpolation of population data of socio-economic statistic data; the vegetation cover data from inversion of TM image in June, 2007.

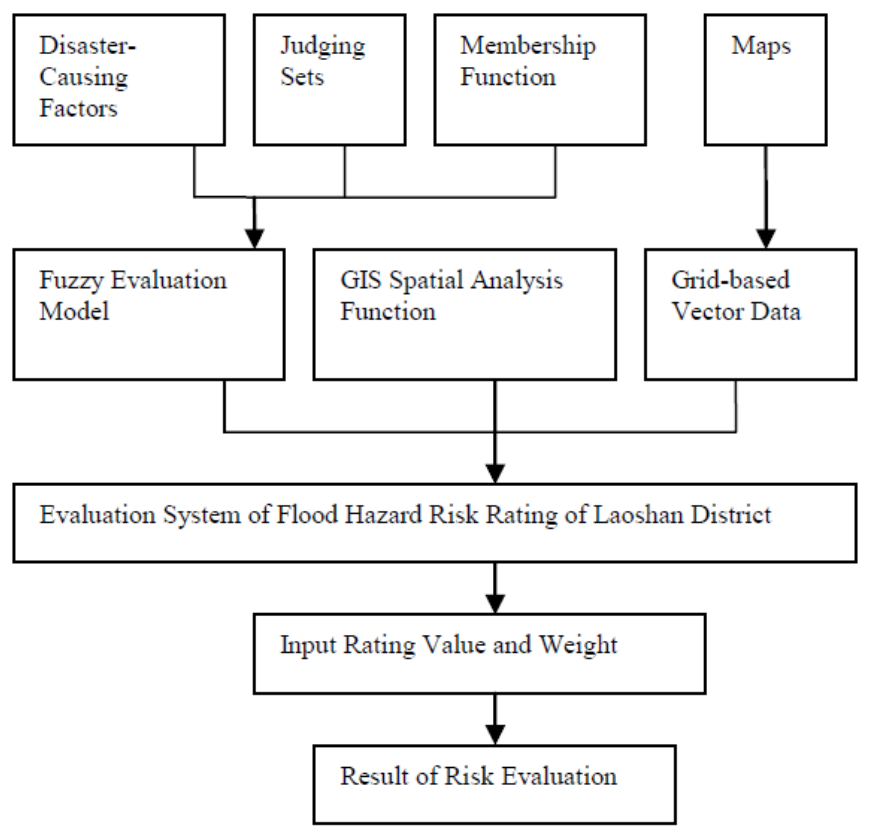

Figure 2. Scheme of Evaluation System on Flood Hazard Risk of Laoshan District

\section{2) Grid-based vector data}

With ArcGIS, the vectorized administration area dividing data was converted into grid-based shape file data. The file contained 9750 grids with a resolution of $200 \mathrm{~m} * 200 \mathrm{~m}$, and each grid was taken as an independent response unit. The above resolution assured the existing consistency of spatial variation of disaster causing factors and continuity of variation between grids. Referring to distribution of each factor in map, data of each assessed grid was input into database, which was based on that each factor involved into the evaluation which was taken as field stored into database. So data of the whole studied region was discretized into those square vector grids. the fields in the database could match impact factors in model. Every record represented block with length of $200 \mathrm{~m} * 200 \mathrm{~m}$, equal to one evaluated cell.

\section{3 ) Judging sets and membership grade}

Mainly referring to existing flood hazard survey data, relevant researches ${ }^{[17]}$ and standards, after quantitatively grading each factor, grading schedule of evaluation factors of 
flood hazard risk in Laoshan District was constructed, and which is shown in table 1 .

For complexity of disaster environmental system, risk here did not contain absolute meaning. The general grading method often adopts logic information category method or feature category method, with which the studied object is divided into 3 or 5 levels ${ }^{[18]}$. In this study, we divided result into 5 grades, that was Criteria Set: $\mathrm{V}=(1,2,3,4,5)$. So value of each factor was sorted into 5 ranks, which are the safest (1 level), safe (2 level), normal (3 level), dangerous (4 level), and the most dangerous (5 level).

TABLE I Rating the Disaster-causing Factors

\begin{tabular}{cccccc}
\hline Disaster-Causing & 1 & 2 level & $\begin{array}{c}3 \\
\text { Factors } \\
\text { level }\end{array}$ & $\begin{array}{c}4 \\
\text { level }\end{array}$ & 5 level \\
Rain Intensity & 3 & 4 & 5 & 6 & 7 \\
$\begin{array}{c}\text { Gradient }\left(^{\circ}\right) \\
\text { Drainage Density } \\
\left(\mathrm{km} / \mathrm{km}^{2}\right)\end{array}$ & 0 & 10 & 20 & 30 & 40 \\
$\begin{array}{c}\text { Population Density } \\
\left(\text { Person } / \mathrm{km}^{2}\right)\end{array}$ & 200 & 300 & 400 & 500 & 600 \\
$\begin{array}{c}\text { Vegetation Cover (\%) } \\
\text { Rainfall }(\mathrm{mm})\end{array}$ & 80 & 60 & 40 & 20 & 0 \\
\hline
\end{tabular}

\section{4) Construction of weight sets}

For there exist contributions between factors trigging flood hazard, it is vital for correctly evaluating risk to analyze interaction and correlation between factors, and define their status and impact in the whole evaluation system respectively.

Following the rule of AHP ${ }^{[19,20]}$, by means of multiple comparisons, a judge matrix was constructed, and therefore, by which we could ultimately calculate weight of each factor, that is shown in table 2 .

TABLE II Weight of Factors

\begin{tabular}{cccccc}
\hline $\mathrm{U} 1$ & $\mathrm{U} 2$ & $\mathrm{U} 3$ & $\mathrm{U} 4$ & $\mathrm{U} 5$ & $\mathrm{U} 6$ \\
0.298 & 0.228 & 0.109 & 0.053 & 0.081 & 0.231 \\
\hline
\end{tabular}

\section{5) Evaluation and Calculation Process}

In term of the above comprehensive evaluation principle, adoption of weighted mean model, we can acquire membership of each factor by computing data of each grid pursuant to membership function. Furthermore, the above memberships were used to establish the matrix R. following the above step, comprehensive evaluation hierarchical matrix $\mathrm{B}(\mathrm{B}=\mathrm{A} \times \mathrm{R})$ was accomplished. Finally, we got evaluation values in rank, by normalizing matrix $\mathrm{B}$ in accordance with weighted mean model.

\section{$B$ Realization of Function of the Program}

By the aid of seamless integration of VB Net 2005 with ArcEngine 9.2, with emphasis on fuzzy comprehensive evaluation model, we developed the software system which was based on GIS technology. On running the system, the users firstly build new final evaluation hierarchy fields, and select related judgment factors in rank calculation dialog box, then input rank value and weight value of each factor. Ultimately, with running embedded programmed fuzzy evaluation model, evaluation class will be acquired. The software system can export evaluation results in the form of thematic map which was plotted by evaluation rank field in the relevant database. The figure 2 shows the visual result of risk rank spatial distribution of flood hazard in the studied region which was made by the software system.

\section{Evaluation Result Analysis}

As figure 2 shows, area of the most dangerous place was $1.8 \%$ of total area. It mainly sites in Baishitoujiao, Baozigu,Sangshiwu and Dongxiqi, all of which belongs to the Wanggezhuang Street Agency, and the rest of it sites in Houchao of the Shazikou Street Agency. It has been recorded that a flood-causing debris flow was occurred, known as Dahedongcun debris flow. The historical record was much identical to the evaluation result.

Area of the dangerous place was $14.1 \%$ of the studied region. It mainly sites in the Wanggezhuang Street Agency, among which Shiwujian, Xiejiahe are at the north, Zhangiiacun, Liujiacun and Caijiacun are at the middle and Qianjian, Dapinlan are at the south. The other of the type sparsely distributes in the east of the Beizhai Street Agency.

Area of the normal place was $42.6 \%$ of the studied region. It mainly sites in the Shazikou Street Agency, among which Zhuwo, Liushutai, and Zhoulan locate in the north, Xiaohedong, and Daanzi locate in the middle, and Heishigou, and Xinfucun site in the South, respectively. The other distributions of the type include Lijia and Sunjiacun, both were in Beizhai Street Agency, Puli and Liujiawo, both were in north of the Wanggezhuang street agency.

Area of the safety zone was $37.6 \%$ of the total studied area, that nearly covers the whole Zhonghan Street Agency. The other distributions of the type include the south-west of the Shazikou Street Agency, the middle and the west of the Beizhzi Street Agency.

The safest zone mainly locates at Bijiacun, Wulongcun, Dongchencun, where was in Beizhai Street Agency, Beilongkou and Nanlongkou, both were in the Shazikou Street Agency.

The most dangerous and dangerous zones mainly locate in region of the Wanggezhuang. Majority of the normal zone distribute the Beizhai and Shazikou. Therefore, it was evident that the least susceptibility of flood hazard were in the Zhonghan. In other word, the Wanggezhuang should be taken as key region to secure from potential flood hazard.

\section{Conclusion}

Integration of fuzzy mathematics with GIS has made the study more effective, scientific and credible to evaluate risk of flood hazard. The system we have developed is a easy-to-use intuitive software. It can offer friendly visual GUI, radical 
spatial analysis functions, and many thematic map making functions. As a user of the software, you will not have to learn how to use GIS software, only follow prompts given by the system to input weight value and rank value for the membership function. The present investigation has suggested that the results offered by the system have more consistent with in-situ sites where flood hazard have occurred. Those studies have provided that methodology adopted by the study is scientific and index system of the evaluation is accurate. The model embedded into the system has much superiority of strong generality which is presented that once some corresponding parameters are modified, it can be applied into the other domains. Of course, there still exists some defects need to prefect next. For instance, the evaluation system needs totality of the hazard making factors and enhancing of the software running speed.

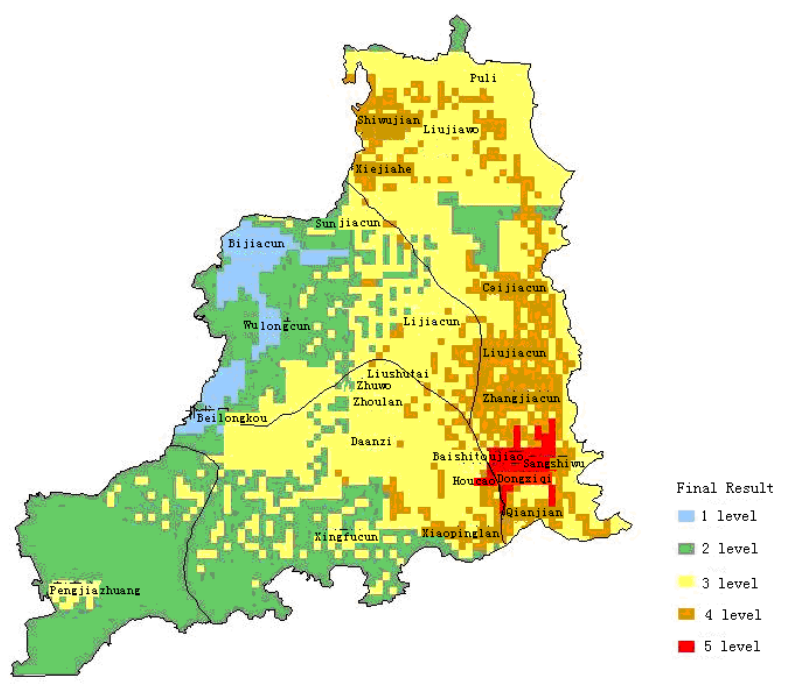

Figure 3. Final evaluation result of rating risk of flood hazard in Laoshan District

\section{Acknowledgment}

The study was funded by research project of State Oceanic Administration (SOA), title of it is "Demonstration Research of Monitoring and Early Warning Typical Island Geological Hazard in China" (Grant No: 201005010).

\section{References}

[1] Zhang Hui, Zhang Jiquan, et al. GIS-based Assessment and Zoning of Flood/Waterlogging Disaster risk: A Case Study on Middle and Lower Reaches of Liaohe River [J]. Journal of Natural Disasters, 2005,14(6):141 146
[2] Robert L Schuster. Concepts of Risk-based Decision Making with Emphasis on Eotechnical Engineering and Slope Hazard [M].// Geotechnical Risk Management, 1999:1 21

[3] Zhang Jincun, Wei Wenqiu, Ma Wei. A Research on the Remote Sensing Monitoring and Analysis System of Flood Disaster [J]. Journal of Catastrophology, 2001,16(1): 39 44

[4] Gao Huiyan, Wang Sufang, Wang Yanqin, et al. Probe into Optimization of Flood Disaster Evaluation Model [J]. Heibei Water Resources and Hydropower Technology, 2004(1): 34 36

[5] Wahlstrom E, Loague K, Kyriakidis P C. Hydrologic Response: Kaho'olawe, Hawaii [J]. Journal of Environmental Quality, 1999,28(2):481 492

[6] Xu Zhisheng, Feng Kai, Feng Chunying. Application of VR-GIS Technology to Analysis and Simulation of Flood Undulation Small Towns [J]. China Civil Engineering Journal, 2003,36(5):247 251

[7] Ma Anqing, Hu Hong, An Xinqin, et al. Using GIS to simulate Distribution of Ground Concentration of Urban Air Pollution [J]. Urban Environment \& Urban Ecology, 2007,20(2): 32 34

[8] Gong Qinghua, Huang Guangqing, Guo Min, et al. GIS-based risk Zoning of Flood Hazard in Guangdong Province [J]. Journal of Natural Disasters, 2009,18(1):58 63

[9] Yin Mingquan, Tan Junling, Wang Zhiliang, et al. Experimental Geohazard Warning based on Weather Forecasting of Laoshan District,Qingdao City [J]. Hydrogeology and Engineering Geology, 2006,33(2):96 100

[10] Yin Y Y, Huang G H, Hipel H K, et al. Fuzzy Relation Analysis for Multi-criteria Water Resources Management [J]. Journal of Water Resources Planning and Management. 1999,125(1):41 47

[11] Sasikumar K, Mujumdar P P. Fuzzy Optimization Model for Water Quality Management of A River System [J]. Journal of Water Resources Planning and Management, 1998,124(2):79 88

[12] Hou Yingzi, Chen Xiaoling, Wang Fangxiong. Fuzzy Comprehensive Evaluation of Water Environment Value Based on GIS [J]. Scientia Geographica Sinica, 2008,28(1):89 93

[13] Mejia-Navarro, Wohl E E. Geological Hazard and Risk Evaluation Using GIS: Methodology and Model Applied to Medellin, Colombia [J]. Bulletin of the Association of Engineering Geolosists, 1994,31(4):459 481

[14] Van Westen C J, Van Asch T W J, Soeters R. Landslide Hazard and Risk Zonation: Why Is It Still So Difficult [J]. Bulletin of Engineering Geology and the Environment, 2005,65(2):176 184

[15] Song Guanfu, Zhong Ershun. Research and Development of Components Geographic Information System [J]. Journal of Image and Graphics,1998,3(4):313 317

[16] Liu Hongyan, Sun Xihua. GIS Based Sensitivity Evaluation of Soil Erosion in Ji'Nan City [J]. Bulletin of Soil and Water Conservation, 2008,28(2):127 130

[17] Zhang Yecheng Hu Jingjiang Zhang Chunshan. Hazardous Analysis and Zonation of China Geological Disasters [J]. Journal of geological hazards and environment $\mathrm{p}$ reservation, 1995,15(3):55 67

[18] Li Peiying, Du Jun, Liu Lejun. Geologic Features and Evaluation of disasters on Chinese Coastal Zone [M]. Bejing: China Ocean Press, 2007:207 218

[19] Zhang Zhen, Wang Longchang, Yang Song, et al. Study on the AHP Comprehensive Evaluation of Sustainable Water Resource Utilization of Sichuan Province [J]. Agricultural Research in The Arid Areas, 2009(4):213 218

[20] Liu Tao, Zhang Hongjiang, Wu Jingdong, et al. Application of Analytic Hierarchy Process in Debris Flow Risk Degree Assessment - - A Case Study of Miyun County, Beijing City [J]. Bulletin of Soil and Water Conservation,2008,28(5):6 10 